\title{
BINNENGEKOMEN BOEKEN
}

The Sixth Council Directive on Value Added Tax (Uniform Basis of Assessment)

Pierre Guieu

Uitgeverij Kluwer B.V. te Deventer

Prijs $f$ 26,50

Comptabilité Générale. Université et Technique

André Cibert

Uitgeverij Bordas te Parijs

Toepassing van actuele waarden in de jaarrekening (NIVRA-geschrift no, 18)

Uitgeverij Kluwer B.V. te Deventer

Prijs $f 17,50$

Aspecten van de belastingheffing van coöperatieve verenigingen

(Fed's Fiscale Brochures Vpb: 3.4)

Mr. A. G. F. Lindeijer

Uitgeverij Fed B.V. te Deventer

Prijs $f 14,95$

Compendium van de Omzetbelasting

Mr. J. M. F. Finkensieper

Uitgeverij Kluwer B.V. te Deventer

Prijs $f$ 25,-

Inflatie en belastingheffing (2)

Bespreking van het rapport van de Commissie ter bestudering van de relatie tussen inflatie en belasingheffing

(Geschriften van de Vereniging voor Belastingwe. tenschap no. 146)

Uitgeverij Kluwer B.V. te Deventer

Prijs $f 14,50$

Het ontwerpen van informatiesystemen; een inlei ding

W. Hartman

Uitgeverij Kluwer B.V. te Deventer

Prijs $f$ 14,-

Kostencalculatie en waarderingsproblemen $4 \mathrm{e}$ druk)

(Serie De Moderne Onderneming)

Dr. Jac. Koolschijn en Drs. H. E. Wijnberg

Uitgeverij Samsom B.V. te Alphen aan den Rijn

Prijs $f$ 54,90

Onderneming en jaarverslag (5e druk)

J. M. Vecht

Uitgeverij Samsom B.V. te Alphen aan den Rijn Prijs f' 36,90
Welvaartstheorie en economische politiek

Prod. Dr. P. Hennipman

Uitgeverij Samsom B.V. te Alphen aan den Rijn

Prijs $f 32,50$

Het ontwerpen van formulieren (5e druk)

Th. H. Oltheten en K. Steenwijk

Uitgeverij Staatsuitgeverij te Den Haag

Prijs $f 29,50$

Management in de Rijksdienst

(Een vergelijkende verkenning in 30 eenheden van de centrale overheid)

Projektleider Dr. J. Kastelein

Samengesteld door het Instituut voor Bestuurskun. de van de Universiteit van Amsterdam, in opdracht van het Ministerie van Binnenlandse Zaken

Comptabiliteitswet 1976. Bedrijvenwet 1928 (9e druk)

Bewerkt door K. H. P. Loncke

Nederlandse Staatswetten. Editie Schuurman \& Jor dens (20)

Uitgeverij W. E. J. Tjeenk Willink B.V. te Zwolle

Prijs $f 9,50$

Financieel Memo 1977

Uitgeverij Kluwer B.V. te Deventer

Prijs $f 13,50$

Tussen verwarring en verstarring

Rede uitgesproken bij de aanvaarding van het ambt van gewoon lector in het belastingrecht aan de Rijksuniversiteit te Groningen door Mr. D. Booij

Uitgeverij Kluwer B.V. te Deventer

Prijs f $9,-$

Het fiscale rechtstekort

Rede uitgesproken bij de aanvaarding van het ambr van gewoon hoogleraar in het belastingrecht aan de Rijksuniversiteit te Leiden door Mr. J. F. M. Giele Uitgeverij Kluwer B.V. te Deventer Prijs $f$ 9,-

Elementair belastingrecht voor economisten (vierde herziene druk)

Prof. Dr. B. Schendstok/Prof. Drs. A. L. Brok/Drs. L.

G. M. Stevens

Uitgeverij Kluwer B.V. te Deventer

Prijs $f$ 29,-

Regelmatig boekhouden met geregelde jaarlijkse af. sluitingen en winstberekeningen per boekjaar (Fed's Fiscale Brochures, IB: 3.49)

J. Brautigam

Uitgeverij Fed B.V. te Deventer

Prijs $f 8,20$ 
Fiscaal Memo (januari 1978)

Uitgeverij Kluwer B.V. te Deventer

Prijs f 14,-

Kluwers Belastinggids 1978

Uitgeverij Kluwer B.V. te Deventer

Prijs $f$ 11,-

De jaarrekening. Bedrijfseconomische, juridische en fiscale aspecten (tweede druk)

Drs. Mr. H. Beckman/Dr. C. A. Buningh

Uitgeverij H. E Stenfert Kroese B.V. te Leiden

Prijs $f$ 44,50

Onderneming en vermogensmarkt (Bedrijfsecono mische Monographieën)

Dr. G. Rietkerk

Uitgeverij H. E. Stenfert Kroese B.V. te Leiden

Prijs $f 39,50$

De Nederlandse successiewetgeving (Serie Fiscale Hand. en Studieboeken) (tweede druk)

Prof. Mr. H. Schuttevảer

Uitgeverij Kluwer B.V. te Deventer

Prijs $f 72,50$
Van Keynes tot Keynes (De ontwikkeling van het denken over geld en werkloosheid bij Keynes)

Dr. A. Nentjes

Uitgeverij Wolters-Noordhoff te Groningen

Prijs $f 44,50$

Wiskunde voor het economisch onderwijs, deel 1 (tweede druk)

Drs. J. de Koning/J. Smit/Drs. T. V. J. Galama Uitgeverij Educaboek B.V. te Culemborg

Prijs $f 18,50$

Demokratie en welvaartstheorie (tweede herziene druk)

Prof. Dr. J. van den Doel

Uitgeverij Samsom B.V. te Alphen aan den Rijn Prijs $f$ 26,50 